\title{
La creciente medicalización de la vida: ¿somos los médicos conscientes de los perjuicios que produce?
}

\author{
The growing medicalization of life: Are physicians aware of the damage that \\ produces?
}

La medicalización de la vida y la muerte no es reciente y en occidente probablemente comenzó a fines del siglo XVIII junto al desarrollo de la ciencia que emergía, siguió en el siglo XIX y notoriamente en el XX. Sin embargo, es en los últimos 50 años que fue intensificándose cada vez más y lo alarmante es que no hay indicios de que su crecimiento esté menguando y ni que muestre tendencia a disminuir. No obstante, hay médicos y otros profesionales de la salud, como así también de otras disciplinas, en especial las Ciencias Sociales, que manifiestan una gran preocupación por el alcance que tiene este proceso y los perniciosos efectos que produce, tanto en la vida de las personas como en la misma profesión médica.

En estas líneas trataré de enfatizar por qué este fenómeno de ninguna manera es inocuo, $\mathrm{y}$, asimismo, señalar que es imprescindible para nosotros los médicos reflexionar sobre él, ya que sin duda se aparta de las metas de la medicina y de los principios morales y éticos de nuestra profesión.

\section{¿Cómo definimos la medicalización?}

La respuesta no es fácil ni hay una sola definición que incluya todas sus facetas y describir detalladamente su gran complejidad. En forma simple, sería la expansión de la medicina más allá de su campo tradicional y su presencia en múltiples aspectos en la vida de la gente, que hasta hace unos años no se consideraban dentro de la índole médica. Es así que leves y ocasionales molestias se transforman en enfermedades y lo mismo sucede con diversos procesos, entre otros: vejez, infelicidad, soledad, tristeza, desamparo, aislamiento, desempleo, etc., que ingresan en la esfera médica. Cualquier trastorno puede considerarse una enfermedad y de esa manera en la práctica de la medicina aumentan los médicos que suponen que los pacientes sanos son "enfermos mal estudiados", lo cual incrementa marcadamente el mercantilismo mediante el uso excesivo de medicamentos y solicitud de estudios.
Todo esto, representa una modificación sustancial de la visión de los procesos naturales del ciclo vital al verlos en forma excluyente como cuestiones de índole médica o psicológica. Muy probablemente se obtuvieran mejores resultados si esos procesos no fueran incluidos en el ámbito de la medicina.

Es así que un problema no médico pasa a ser un problema médico, es descrito en lenguaje médico y tiene un marco de referencia médico, lo cual produce efectos perjudiciales en las personas.

La medicalización comenzó a ser considerada como no deseable desde que se analizó desde el punto de vista social al ser algo que incidía fuertemente en las culturas y costumbres de la sociedad. El escritor inglés G. K. Cherteston en su libro Lo que está mal en el mundo incluyó en la primera parte, titulada "El desamparo del hombre", un ensayo denominado "El error clínico" (Obras completas. J Janés, Barcelona, 1952) señalando la falacia de ciertos argumentos científicos que mediante la descripción exhaustiva de una enfermedad social propone luego la correspondiente medicación.

Este proceso, donde la medicina y los médicos "invaden" terrenos ajenos a su disciplina, cobró mayor notoriedad con el filósofo austríaco Ivan Illich en su libro Némesis Médica (Ed. Barral,1975). Illich fue un acerbo crítico de la medicina y de los médicos y si bien muchos de sus conceptos son discutidos, es indudable que fue uno de los primeros en señalar lo que luego se denominó "el modelo médico hegemónico" referido al poder de la medicina para incluir en su ámbito cosas ajenas y de esa forma tener una omnipresencia en la vida de las personas. Esto estimuló la cada vez mayor medicalización basado en la errónea creencia de la gente acerca del endiosamiento de los médicos y que por lo tanto la medicina podía solucionar todos o la gran mayoría de sus problemas. Es interesante señalar que en la mitología griega la némesis era el castigo para aquellos que intentaban o creían ser un dios en lugar de un ser humano. 
En la medicalización hay al menos dos actores principales, en primer lugar nosotros, los médicos y luego la sociedad cada vez más adicta a la novedad y deseosa que la medicina utilice el poder que tiene para satisfacer la creciente obsesión de lograr una salud perfecta y el cuerpo "siempre joven". Eso ocurre más notoriamente en los países desarrollados occidentales, aunque se está expandiendo a países con recursos más limitados produciendo uno de los problemas más críticos que es la inequidad en el cuidado de la salud.

Asimismo, otro resultado deletéreo de su expansión, es la creación de nuevas enfermedades o trastornos para incrementar el consumo de medicamentos y métodos diagnósticos que no son necesarios. En este proceso participan cuatro actores, los principales somos los médicos y las industrias farmacéuticas y biotecnológicas, en tercer lugar la sociedad consumista de esta era y finalmente, las erróneas e insuficientes políticas del Estado en salud pública. Se trata de un proceso sumamente complejo que merece múltiples miradas que las mencionaré brevemente pero sin tratarlas en profundidad.

El proceso responde en gran medida al convencimiento de muchos médicos, y por ende de las industrias (complejo médico-industrial) de que la medicina científica tiene una eficacia inapelable y que todas sus acciones son beneficiosas.

Es así que al extender sus fronteras, se expanden cada vez más los mercados para nuevos productos; "de esta forma, se puede obtener mucho dinero de personas sanas que creen que están enfermas" (Moynihan, 2002). En general la gente suele aceptar esta conducta y con frecuencia la demanda. De ahí el común comentario: "fui al médico, me revisó muy bien pero no me dio nada para tomar ni me pidió análisis".

Ya en la década del 70, el filósofo francés Foucault, que tuvo una posición muy crítica de la medicalización, señaló: "en la medicina se genera riqueza en la medida que la salud constituye un deseo para unos y un lucro para otros".

Esta medicina va de la mano del asombroso desarrollo tecnológico, que para muchos es la base esencial del conocimiento científico, algo que no comparto. La "Era tecnológica" creó múltiples beneficios, pero también generó múltiples efectos indeseables, entre ellos la mercantilización de la medicina originando la pérdida de sus metas originales y los principios éticos. Este aspecto no sucede por la tecnología en sí misma, sino por el inadecuado uso que se le da.

La idea generalizada en la sociedad actual de que con la tecnología se puede lograr una vida "cada vez mejor" tiene una influencia perniciosa y contribuye a generar la falsa premisa de que el progreso es ilimitado.

Asimismo, el aumento en la prescripción de medicamentos para todo tipo de dolencias, incluso cuando no está probado que sean útiles, genera progresivamente un consumo excesivo que en la gran mayoría de las veces es injustificado y acarrea el riesgo de efectos adversos.

Otro aspecto es el de los sistemas de pesquisa para detectar posibles trastornos presentes o futuros. Varios de ellos tienen evidencia de sus beneficios en especial en personas con mayor riesgo de padecer una enfermedad pero otros no están sustentados sólidamente. En estos casos se somete a personas sanas a depender de la asistencia médica sin comprobación de que los estudios tengan influencia en la expectativa de vida.

Este sistema y el excesivo uso de métodos auxiliares de diagnóstico, tan en boga en la práctica médica actual, contribuye a aumentar notablemente los costos, que sin duda llevan a una medicina no sustentable, y asimismo, al creciente lucro de los actores que participan. Como bien aseveró el filósofo argentino Mario Bunge "la medicina no puede tener fines de lucro, porque el lucro no tiene límites".

La medicalización de la muerte también es notoria. En nuestra cultura no es aceptada y suele ser un tema "tabú". Muchos acuden a la medicina para que les indiquen estudios diagnósticos y remedios "milagrosos", sin entender que la muerte es inevitable y no constituye solo una cuestión médica. Sin embargo, la medicina participa cada vez más y es así que hoy en día la gran mayoría de las personas no puede morirse en la casa junto a sus afectos y se muere en centros médicos, con frecuencia en la terapia intensiva sin sus familiares.

Finalmente, trataré de responder a la pregunta del título. Surge claramente que los médicos tenemos el protagonismo principal en la medicalización. Sin nuestra participación ese proceso disminuiría en forma marcada. Debemos reflexionar sobre los perjuicios que ocasiona en la gente y en nuestra profesión y bregar para limitar que continúe su expansión y de ser posible disminuya. Aquellos que llevamos más 
años en el ejercicio profesional debemos liderar la recuperación y mantenimiento de los principios éticos que siempre nos deben guiar. Es imprescindible inculcar esos principios a los más jóvenes, comenzando en la Universidad y en las etapas posteriores de formación.
Por supuesto que la tarea no es nada fácil pero todo lo que hagamos, aun en pequeña escala, redundará en evitar o disminuir el daño, un imperativo ético esencial de nuestra profesión.

José M. Ceriani Cernadas

Editor

http:/ /dx.doi.org/10.5546/aap.2012.459

La conclusión es que sabemos muy poco y sin embargo es asombroso lo mucho que conocemos.

$Y$ más asombroso todavía que un conocimiento tan pequeño pueda dar tanto poder.

BERTRAND RusSELL 